\title{
The drama in the hybrid OR: video observations of work processes and staff collaboration during endovascular aortic repair
}

This article was published in the following Dove Press journal:

Journal of Multidisciplinary Healthcare

\author{
May Bazzi' \\ Solveig M Lundgren' \\ Mikael Hellström ${ }^{2}$ \\ Isabell Fridh ${ }^{3}$ \\ Karin Ahlberg' \\ Ingegerd Bergbom' \\ 'Institute of Health and Care Sciences, \\ Sahlgrenska Academy at Gothenburg \\ University, Gothenburg, Sweden; \\ ${ }^{2}$ Department of Radiology, Sahlgrenska \\ University Hospital and Sahlgrenska \\ Academy, Gothenburg University, \\ Gothenburg, Sweden; ${ }^{3}$ Faculty of Caring \\ Sciences, Work Life \& Social Welfare, \\ University of Borås, Borås, Sweden
}

Introduction: A hybrid operating room (OR) is a surgical OR with integrated imaging equipment and the possibility to serve both open surgery and image-guided interventions.

Aim: This study aimed to investigate the work processes and types of collaboration in a hybrid OR during endovascular aortic repair (EVAR).

Methods: Data consisted of video recordings from nine procedures, with a total recording time of $48 \mathrm{hrs} 39$ mins. The procedures were divided into four episodes (Acts). A qualitative cross-case analysis was conducted, resulting in a typical case. The type of collaboration during specific tasks was discussed and determined based on Thylefors' team typology.

Results: An extensive amount of safety activities occurred in the preparation phase (Acts 1 and 2), involving a number of staff categories. After the skin incision (Act 3), the main activities were performed by fewer staff categories, while some persons had a standby position and there were persons who were not at all involved in the procedure.

Discussion: The different specialist staff in the hybrid OR worked through different types of collaboration: multi-, inter- and transprofessional. The level of needed collaboration depended on the activity performed, but it was largely multiprofessional and took place largely in separate groups of specialties: anesthesiology, surgery and radiology. Waiting time and overlapping tasks indicate that the procedures could be more efficient and safe for the patient.

Conclusion: This study highlights that the three expertise specialties were required for safe treatment in the hybrid OR, but the extent of interprofessional activities was limited. Our results provide a basis for the development of more effective procedures with closer and more efficient interprofessional collaboration and reduction of overlapping roles. Considerable waiting times, traffic flow and presence of people who were not involved in the patient care are areas of further investigation.

Keywords: hybrid operating room, work processes, collaboration, tasks, video recording, cross case analysis

\section{Introduction}

Hospital environments are becoming increasingly complex, technique intensive and specialized. This is particularly evident in surgical environments where less invasive image-guided treatments are replacing open surgeries. This development has created the emergence of operating rooms (ORs) with extended imaging capabilities while maintaining the ability to serve as rooms for open surgery. These modern ORs are an integration of a traditional OR with an interventional radiologic room and is called hybrid ORs. ${ }^{1-3}$ The competence requirements to work in a hybrid OR
Correspondence: May Bazzi

Institute of Health and Care Sciences, Sahlgrenska Academy at Gothenburg University, Box 457, 40530 Gothenburg, Sweden

Tel +4 6700761603

Fax +463I 7866050

Email may.bazzi@gu.se 
differs from those of a traditional OR and usually advocate involvement of three specialties that are not used to work together: radiology, surgery and anesthesiology. ${ }^{2}$ One question this raises is if and how staff from different cultural and educational backgrounds collaborate in a hybrid OR and their efficiency.

\section{Previous research and theoretical frame}

Although the number of hybrid ORs in hospitals has increased in the last decade, research about their potential utilization, benefits and limitations remains scarce. ${ }^{4}$ A literature search results in few empirical publications based on the professionals' own experiences of using a hybrid $\mathrm{OR}^{5,6}$ or discussions about the usefulness and potential benefits of a hybrid OR. ${ }^{1,2,7}$ Some studies have focused more on the technical aspects that affected decision-making for building a hybrid OR. ${ }^{7-13}$ Other studies have highlighted the technical opportunities of a hybrid OR including the possibility to convert, for instance, an endovascular treatment to open surgery, as the most important benefits. ${ }^{1}$ There is a lack of literature on the work process and necessary collaboration for the staff within the hybrid OR.

Collaboration between staff with different expertise is abundantly described in the literature where collaboration obstacles, regarding a lack of consensus in relation to new skills, hierarchical valuations and role boundary conflicts, are evident. ${ }^{14}$ In relation to collaboration, the term team is often mentioned and defined differently in the literature. In this paper and context, team can be operationalized as a group of staff members who are required to work together toward a common goal, such as a successful medical treatment. This definition excludes how the team is functioning or should function in terms of collaboration. The term cross-professional refers to collaboration between several specialties but does not tell in what way the collaboration occurs. Depending on the number of interactions and mutual dependency among team members, collaboration can be divided into multi-, inter- or transprofessional. $^{15,16}$ In a multiprofessional team, the members contribute independently and work in parallel to care for the patient. Members of an interdisciplinary team work together closely and communicate frequently. A transprofessional team is the opposite end of the continuum of a multiprofessional team; team members work very closely and have mixed roles which means that different members can take on each other's role if deemed necessary. ${ }^{16}$
In the hybrid OR context, the team function is essential, ${ }^{17-19}$ but the practical work and collaboration between the staff remain largely unknown. Such knowledge is of importance for achieving patient safety, good work environment for the staff and effective work processes.

\section{Aims}

The aim of the study was to describe the work processes and collaboration in a hybrid OR during endovascular procedures where staff categories from anesthesia, surgery and radiology were involved. We aimed to generate knowledge about the new phenomenon of work processes and collaboration in a hybrid OR and highlight previously uninvestigated aspects during real procedures. Two of the main questions were: 1) What care and treatment activities were performed during the procedure by which staff category and 2) When and how did staff from different specialties (anesthesia, surgery and radiology) collaborate during the procedure?

\section{Methods}

We included endovascular procedures, more specifically endovascular aortic repairs (EVARs), which are the most common procedures done in the hybrid OR within a Swedish context. The current study was a non-participative, observational study with a descriptive and interpretive design. As one of the goals of our study was to investigate the new phenomenon "work processes and collaboration in a hybrid OR", we conducted an observational study with a low degree of structure, as recommended by Einarsson and Hammar Chiriac. ${ }^{20}$ Based on our research questions together with the nature and complexity of the hybrid OR context, we decided to video record the procedures to allow for multiple viewings to ensure accurate analysis.

\section{Setting and definitions}

The study context was a hybrid OR, inaugurated in May 2011, located in a university hospital. The room size was $93 \mathrm{~m}^{2}$ and the imaging system used was a floormounted system called Siemens Artis Zeego system. Figure 1 is an illustration of the hybrid OR in which we conducted our study. The staff that worked in the hybrid OR were specialist physicians, registered nurses (RNs: radiographer, nurse anesthetist and OR nurses) and licensed assistant nurses from both anesthesia and surgery. Collectively, the RNs were called nursing staff throughout 


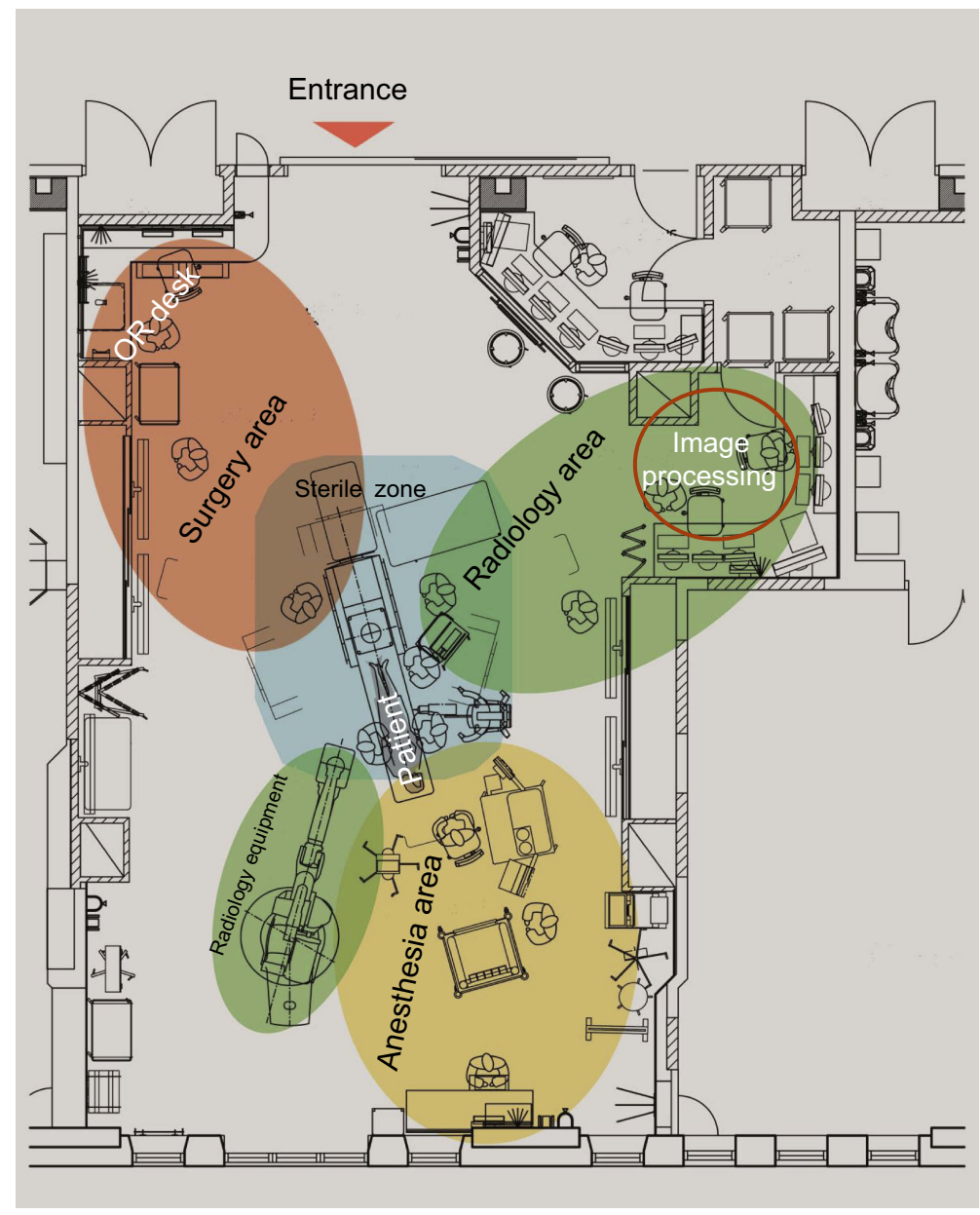

Figure I Landscape of the hybrid operating room. Source: Tyréns Arkitekter used (and modified) with permission from Tyréns Arkitekter.

this study. The physicians were either vascular surgeons or interventional radiologists, referred to as operators. In Sweden, the registered radiographer has a unique position, as he/she is responsible for the technical planning and execution of the entire radiological examination, as well as providing good nursing care to the patient, including administering medications and intravenous injections. The anesthesia and OR nurses both have academic specialist education; however, the assistant nurses have mainly been trained in practical aspects of the job in different specialist areas.

\section{Data collection}

The data of the study consisted of digital audiovisual video recordings of nine EVAR procedures in the hybrid OR as illustrated in Figure 1. All nine patients in the present study were treated in general anesthesia. Two digital video cameras (Sony BRC-z700 and, HD 3 CMOS), which had been previously installed into the ceiling for educational purposes, recorded an overview of the whole room (except for a small area called image processing; see Figure 1). These cameras focused on two opposite areas of the hybrid OR: the inner portion of the room and the area surrounding the entrance.

The two cameras had the ability to send live signals to a video review room located away from the hybrid OR. The cameras had to be activated initially in the hybrid OR but could thereafter be controlled from the video review room. It was then possible to watch the whole procedures on two screens, one for each camera. The audiovisual video recordings allowed simultaneous or separate display on the two monitors. The time and duration of the procedures were noted, and recordings could be replayed in slow motion in the VLC media player. Four microphones were placed to record oral communication in all parts of the hybrid OR. There were three inclusion criteria: 1) procedures had to be elective, 2) the treated patient had to be an adult (18 years or older) and 3 ) the procedure was expected to require staff from all three disciplines: anesthesia, surgery and radiology. A large sign saying, 
"Recording in progress" together with written information about the research project was placed outside the entrance (see Figure 1) of the hybrid OR. The staff in the room were again informed orally by the researcher before each recording commenced. The cameras were then activated by the researcher, and subsequently two signs inside the hybrid OR were automatically activated to say, "Transmission in progress." After confirmation from the staff, the researcher moved to the video review room, and the recording could start. All activity in the room was visually and audibly available to the primary researcher (MB), who was the only attendant in the video review room during the whole recording time. The recording started when the patient was wheeled into the hybrid OR and stopped when the patient left the room. Data were collected from December 2014 to September 2015 and consisted of videos involving nine EVAR procedures on nine patients with a total recording time of $48 \mathrm{hrs} 39 \mathrm{mins}$ (2,919 mins) with a range of $4 \mathrm{hrs} 39 \mathrm{~min}$ to $7 \mathrm{hrs} 32 \mathrm{mins}$ ( 279 mins to $452 \mathrm{mins}$ ). The average procedure time was 5 hrs 24 mins (324 mins).

\section{Data analysis}

All nine videos were reviewed by three observers (MB, IB and SL) with different backgrounds and experience in patient care and treatment in technologically complex environments. Each observer separately made notes on what they had observed on the recorded digital videos prior to discussing them with each other. These notes included video recordings from both cameras. Then, all notes were read and discussed by the observers trying to reach concordance/consensus, sometimes resulting in repeated, joint viewing of the videos. The first impression of the videos was that the procedure, including the tasks performed, could be divided into four episodes, labeled as Acts (see Table 1). In the next step of the analysis, main activities and the involved staff (which were seen as actors) including their collaboration were noted, interpreted and analyzed inspired by Gadamer's ${ }^{21}$ thoughts and descriptions of the "play, acts, and actors." In the final step, a cross-case procedure ${ }^{22}$ with identification of similarities and differences of the typical activities in the nine videos was conducted. This cross-case analysis resulted in characteristics of each Act that could be amalgamated into one paradigm or typical case ${ }^{23}$ used by, for example, Emami ${ }^{24}$ and Melheim. ${ }^{25}$

In the discussions concerning the results, the collaboration type was based upon course/clusters of events and
Table I Definition of the Acts I-4 and their duration in minutes

\begin{tabular}{|c|c|c|c|}
\hline & $\begin{array}{l}\text { Start of } \\
\text { act }\end{array}$ & End of act & $\begin{array}{l}\text { Average } \\
\text { time } \\
\text { (minutes) }\end{array}$ \\
\hline Act I & $\begin{array}{l}\text { Patient enters } \\
\text { the room }\end{array}$ & $\begin{array}{l}\text { Placement of the tracheal } \\
\text { tube }\end{array}$ & 30 \\
\hline Act 2 & $\begin{array}{l}\text { Patient is } \\
\text { intubated }\end{array}$ & $\begin{array}{l}\text { Preparation for the skin } \\
\text { incision with ultrasound } \\
\text { guidance }\end{array}$ & 79 \\
\hline Act 3 & $\begin{array}{l}\text { Start of skin } \\
\text { incision }\end{array}$ & $\begin{array}{l}\text { Skin closure and wound } \\
\text { dressing is finalized }\end{array}$ & 182 \\
\hline Act 4 & $\begin{array}{l}\text { Removal of } \\
\text { surgical sheets } \\
\text { starts }\end{array}$ & $\begin{array}{l}\text { The patient is transported } \\
\text { out of the hybrid OR }\end{array}$ & 33 \\
\hline
\end{tabular}

was reflected upon in relation to the team type index suggested by Thylefors et al. ${ }^{15,26}$ Based on this team type index, the different tasks/activities that occurred were categorized as being multi-, inter- or transprofessional. A multiprofessional activity was considered specialized, and only those with that special professional education could perform the task. An interprofessional activity was also considered specialized, but everyone on the team was expected to interact and be prepared to participate in the task as required. When performing a transprofessional activity, everyone had to be prepared both to complement and to replace each other when necessary. The type of activity was determined by looking at the staff category(ies) performing the activity. If an activity was always performed by a specific staff category(ies) and had a distinct boundary, it was judged to be multiprofessional. When the activity engaged different staff categories and could not be specified to one staff category, it was assessed as a transprofessional activity. All activities that required different staff categories to communicate and help each other for the activity to be completed and where boundaries partly overlapped were considered as interprofessional.

\section{Ethical considerations}

The study was approved by the Regional Ethical Review Board (No. 392-14) and was conducted in accordance with the Helsinki Declaration. ${ }^{27}$ Permission to video/audio record was also obtained from the hospital management. All patients were informed both verbally and in writing in advance, and they had given their written informed consent to participate. The staff were orally informed repeatedly during different staff meetings and had the possibility 
to raise questions and concerns. All staff also received written information by e-mail, and their right to withdraw from participating was clearly explained. Detailed information about the usage, handling, and storage of the data was given. This information included that the data would be available only for the research group, and the videos would be stored in a fireproof locked cabinet and saved in accordance with the Swedish Archives Act. ${ }^{28}$

\section{Results}

The results are presented in two parts. First, the typical case is presented for each Act separately, with Act 2 being subdivided into three scenes due to the amount and variation of events that particularly occurred during this Act. The main staff categories involved and present in the hybrid OR were eight, the vascular surgeon, the interventionist, anesthesiologist, OR nurse, nurse anesthetist, radiographer and assistant nurses from two disciplines (OR and anesthesia). Second, based on the analysis, the main activities and who performed in each Act are presented in Figure 2.

\section{The typical case Act I}

Act 1 started when the patient was wheeled into the hybrid OR by the nurse anesthetist and anesthesia assistant nurse. Inside the hybrid OR an additional nurse anesthetist, OR nurse, OR assistant nurse and sometimes two radiographers were present and greeted the patient. Each category of the attending staff was usually located in the parts of the room designated for their professional tasks (see Figure 1). When the patient bed was parked near the centrally located OR table, all present staff directed their attention to the patient and the forthcoming transfer. The patient was informed by one of the nursing staff about the transfer approach, and the most common transfer action was that the patient bed was situated next to the OR table and the patient was moved laterally, sometimes using a sliding board. Approximately five people from the nursing staff and assistant nurses, standing on either side of the OR table, were involved in this activity. Once the patient was on the OR table, the empty bed was rolled out by the anesthesia assistant nurse. Instructions for adequate positioning were given by the nurse anesthetist to the patient followed by a dialog involving questions about the patient's comfort level. When the correct patient position was achieved, the patient gown was removed by the OR assistant nurse and replaced with a blanket that covered the patient's entire body, usually excluding their feet. Usually both the nurse anesthetist and the OR nurse were around the patient, and the OR assistant nurse took the urine drainage bag and placed it beside the OR table. Two nurse anesthetists were closest to the patient's head, and they occasionally spoke with the patient while performing practical tasks, such as connecting infusions, blood pressure cuffs, pulse oximeters, ECGs (echocardiography) and defibrillator plates.

From time to time, the patient got a pat on the shoulder by the nurse anesthetist or another member of the nursing staff. These moments of contact happened occasionally but mostly when correction of the patient position was being made. Both arms of the patient were laid on armrests at a 90-degree angle from the patient's body by the nurse anesthetist. Most of the staff, except for one nurse anesthetist, occasionally left the room and then returned, but they were mostly engaged in different activities in different parts of the hybrid OR. If present, the radiographer mainly moved in the center of the room, while the OR nurse was mainly located in the surgery area (Figure 1) unlike the OR assistant nurse who moved throughout the room. One (sometimes two) anesthesiologist was already in the hybrid OR or called for when it was time for the anesthesia induction, which was performed by the anesthesiologist and nurse anesthetist. Placement of a peripheral artery catheter was an activity performed by the anesthesiologist with assistance from the nurse anesthetist. At the time for tracheal intubation, a respiratory mask was placed over the patient's mouth and nose, and the nurse anesthetist asked the patient to think about something beautiful. Act 1 ended when the tracheal tube was successfully inserted by the nurse anesthetist.

\section{Act 2}

Many activities in different parts of the hybrid OR were taking place simultaneously in different locations of the hybrid OR (see Figure S1 - online supplementary file). Due to the complexity and number of tasks occurring during Act 2, it was, therefore, subdivided into three scenes.

Scene 1: "The patient was placed in the right position." The main activities in this scene concerned the patient's body and occurred in the center of the room. The correct positioning of the patient's body was a prerequisite for the activities in this phase of the procedure and was performed by all nursing staff and the OR assistant nurse. The patient was placed with both arms out 


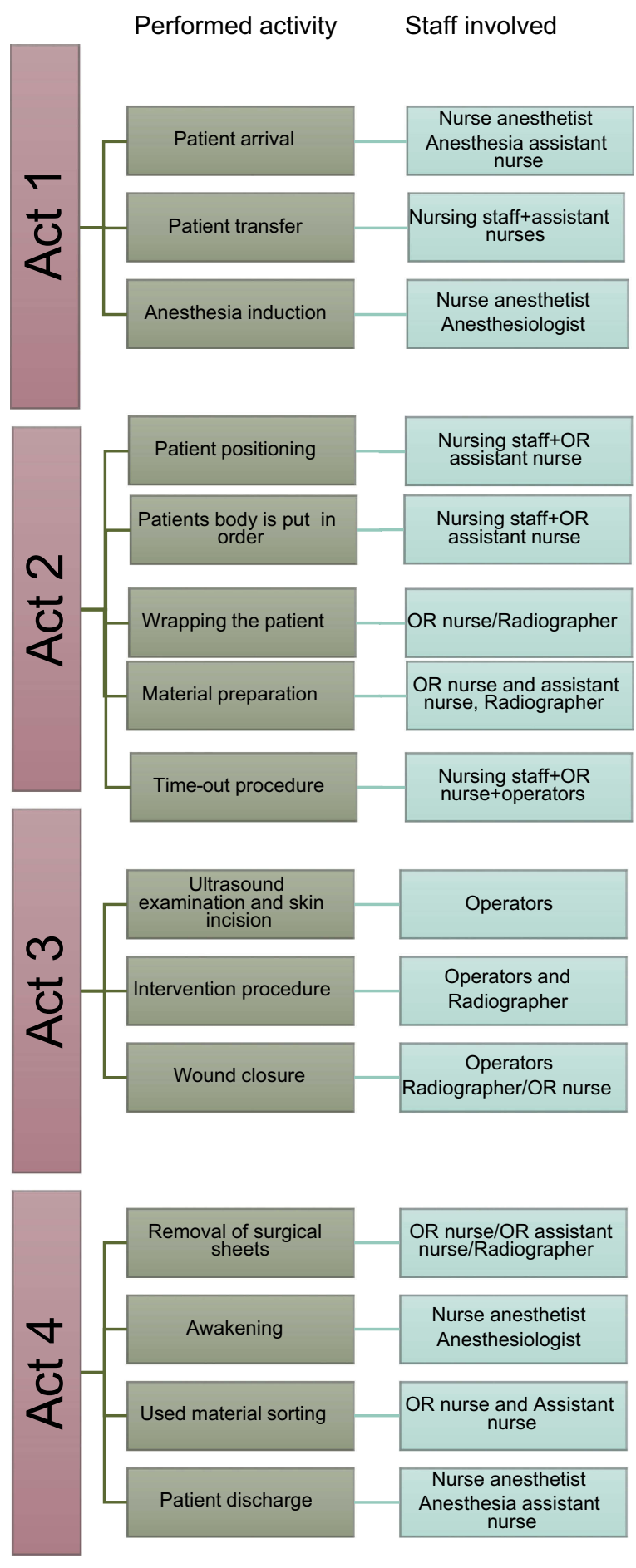

Figure 2 Examples of the main activities related to the patient (body) in each Act and performed by which staff category(ies).

from the body for easy access, for the anesthesia staff to place peripheral vein catheters and connect infusions. The nurse anesthetist generally stayed near the patient's head. The OR assistant nurse had an active role in this scene when he/she after putting on gloves, plastic apparel, and placing protective coats on both sides of the patient, shaved and cleaned the patient's trunk and covered the patient's body with surgical blankets. Pressure relief (foam) cushions were placed under the patient's arms before they were wrapped in a sheet. Sometimes, this led the nurse anesthetist to tell other staff that the monitoring curve was disturbed. A black belt was tightened around the patient's legs. When all staff were pleased, they returned to their area (see Figure 1) in the hybrid OR.

Most commonly, staff from the radiology department (two radiographers) arrived at this time if they had not already arrived during Act 1 . The radiographers entered the room with a hospital trolley with different material on it. They started to prepare for their tasks by moving different equipment and radiation protection devices to the right places in the hybrid OR.

One or two OR nurses walked back and forth or stood near the OR desk (see Figure 1), waiting for an upcoming activity. The staff moved quite actively and there were a number of door openings, as staff walked in or out of the room. Sometimes, the entrance door opened without anyone entering or exiting.

Scene 2: "Material and devices/equipment prepared for the intervention." The main activity was to prepare the material, equipment and patient for the intervention. The OR nurse left the room and returned wearing a surgical mask and a radiation protective apron, waving his/her washed hands to be dried.

The OR nurse got assistance, usually from the OR assistant nurse, when he/she put on a sterile gown. He/she additionally put on sterile gloves and moved closer to the sterile table, removed the protective sheet and started to prepare the specific surgical material. With help from the OR assistant nurse, he/ she cleaned the patient's skin with chlorhexidine and covered the patient's body with several sheets. At the final stage of the dressing, the radiographer started to get dressed in a sterile gown and covered different equipment in plastic. The radiographer then worked in parallel with the OR nurse and another radiographer. In this parallel work, the most obvious scenario was that the OR nurse covered the patient with sterile sheets, while the radiographer covered the equipment. However, these roles were not strict, and they supported each other when needed. The patient's body was now largely invisible under the protective sheets. The nurse anesthetist stayed close to the head of the patient and mostly moved between the patient and the anesthesia equipment.

Scene 3: "We are ready now." In the third scene, the staff had finished their preparations and safety measures, thus, the interventional procedure could start. The operators (usually a vascular surgeon and an interventional 
radiologist) could, therefore, be contacted. The anesthetized patient was in the center of the room while the staff stood ready in different parts of the hybrid OR. The OR nurse had now removed the sterile gown and stood close to the OR desk (see Figure 1). The radiographer, still dressed in a sterile gown, stood close to the patient's feet with his/ her back turned toward the patient. He/she was busy focusing on the sterile table and flushing different interventional material with a saline solution.

The operators entered the room together or within a short time of each other. One of them usually started to talk with the radiographer and/or an OR nurse. The operators analyzed the screens in the image processing area (see Figure 1) and had discussions about the situation. Shortly after, they left the room, returned with radiation protective aprons on and ready to put on a sterile gown with the assistance from the sterile dressed radiographer. When the operators were ready, a timeout procedure based on the WHO Surgical Safety Checklist and Guidelines for safe surgery (World Health Organization, 2009), was conducted. In this procedure, all team members introduced themselves and confirmed the procedure and patient identity. Act 2 ended when one of the operators examined the patient's groin by ultrasound at the area of skin incision.

\section{Act 3}

The third act was the longest in duration (see Table 1) and started with the incision of the skin (artery puncture). Only a small part of the patient's skin was visible (the groin), and most of the working activity occurred on this exposed area.

The main actors were the two operators (vascular surgeon and interventional radiologist) and the sterile dressed radiographer (see Figure S2 - online supplementary file). These three performed the actual intervention, which varied in approach and complexity depending on factors, such as patient anatomy and general overall health. Close collaboration was seen between the operators and the radiographer.

The sterile dressed radiographer's activity included assisting the two operators with material, an ongoing process during all of Act 3 and there was continuous discussion regarding the procedure between these three actors. A second radiographer assisted the sterile dressed radiographer with material and handled the contrast injector and image exposure during the procedure. During imaging exposures, the radiographer communicated with the nurse anesthetist about inducing temporary apnea to avoid blurring the images from respiratory movements. The nurse anesthetist was by the head of the patient throughout the procedure, to monitor the patient's vitals. One or two OR nurses were also continuously in the room and were mostly located near the OR desk, using the computer and talking on the phone or with a colleague. A few times an OR nurse moved closer to the center of the room and watched the ongoing procedure or handed over some material to one of the operators. The OR assistant nurse moved around all parts of the hybrid OR and was engaged in tasks that did not directly involve the patient. He/she sorted packages of materials, checked the material against a paper inventory and spoke on the phone. Additional activity happened when he/she approached the nurse anesthetist and received a test tube of blood and left the room for a while to have it analyzed. In this Act, the majority of the staff stood in the same place except during imaging when the staff moved and took a position behind a radiation protective wall near the entrance of the hybrid OR.

When the procedure was completed, the interventional radiologist removed the sterile gown, and the vascular surgeon continued to apply mechanical pressure over the site of the vascular catheter insertion. The ceiling light was raised, and the radiographer slowly withdrew while the OR nurse again became more active with the vascular surgeon when it was time to suture and dress the wound. Surgical suturing was performed by either the vascular surgeon assisted by the OR nurse or the interventional radiologist and the radiographer. A large wound was usually handled by the OR staff and a small one by the radiological staff. After the incision was closed, the OR nurse or the radiographer continued to dress the wound with protective compresses.

\section{Act 4}

The radiographer was still in the hybrid OR, but the activity had changed to be focused on cleaning and sorting the consumed material. All patient covers were removed by the OR nurse and then a blanket was put over the patient's body. The anesthesiologist returned into the room and the tracheal tube was removed by the nurse anesthetist, and shortly after, one could see the patient moving. The nurse anesthetist communicated with the patient and checked if he/ she could move his/her legs. The nurse anesthetist asked the patient several questions and requested him/her to take deep breaths. The operators remained in the room engaged in postprocedural image reviewing. After a while, one of the 
operators returned to the patient, palpated the feet and communicated shortly with the patient. Several activities were performed by the OR nurse and OR assistant nurse, such as cleaning, recycling of material, documentation and sorting of used material.

After a phone call, the patient bed was brought back in by the anesthesia assistant nurse, and with support from the nurse anesthetist, the bed was parked beside the OR table. The OR nurse, OR assistant nurse and anesthesia staff were again involved in the activity of transferring the patient to the bed. The Act and whole procedure ended when the patient was transported out of the hybrid OR by the nurse anesthetist and anesthesia assistant nurse.

\section{Main activities and staff involved}

Identification and analysis of the main activities performed by which staff category are presented in Figure 2. The main activities related to the patient body in Act 1 involved the anesthesia staff, and the nurse anesthetist had the main role. After anesthesia induction and during Act 2, the main activities involved a wider range of staff categories. These activities included patient positioning and different preparations and safety procedures which basically involved all staff in the room. Another shift in main activities and staff involved appeared in relation to Act 3 where the main activities involved only a few of the staff categories: the operators and the radiographer, who cooperated in the actual performance of the intervention. In the final part of the process, during Act 4, all staff categories but the operators were involved. In this Act, the main activities were dominated by cleaning and sorting consumed material, where the main roles were held by the OR nurse and OR assistant nurse.

\section{Discussion}

\section{Type of collaboration}

We used Thylefors ${ }^{15}$ definitions of different teams and collaboration types in relation to activities in order to further analyze and discuss the findings. Figure 3 illustrates examples of multi-, inter- and transprofessional activities.

\section{Performing one's own expert multiprofessional activities}

Throughout the whole procedure, the anesthesia staff performed their multiprofessional tasks connected to the anesthesia induction mainly in the area behind the patient's head. Placement of the peripheral artery catheter was an obvious multiprofessional activity performed by the anesthesiologist, while tracheal intubation was conducted by the nurse anesthetist. In parts of the procedure, the nursing staff worked independently with specific multiprofessional tasks, such as when the radiographer and the OR nurse prepared material on separate tables and partly during sterile dressing where the radiographer seemed to focus on covering the equipment while the OR nurse dressed the patient. Multiprofessional collaboration was evident in Act 3 where the operator and the sterile dressed radiographer performed the interventional procedure. Collaboration was evident, but different activities belonged to a specific staff category. Examples of that were the ultrasound examination and skin incision, which were the operator's area of competence. A previous study indicated that nursing staff perceive collaboration as low despite the proximity to the physicians. ${ }^{29}$ Our study revealed that staff from different specialties (anesthesia, surgery and radiology) did not work as a cohesive unit but more in their own separate teams (see Figure S1, online supplementary file), also during the interventional procedure itself. The work in separate groups supports results from a study conducted in Sweden in an OR where radiology staff were not involved. ${ }^{30}$ That study argued that working in separate groups is associated with interaction and communication difficulties. However, collaboration could be made more obvious and efficient through increased awareness of each other's roles and by viewing the procedure as a whole. Identifying common tasks, around which to cooperate, could result in more collaboration and perhaps a better, more efficient distribution of tasks and improved time efficiency within the hybrid OR.

\section{Inter- and multiprofessional activities}

All staff together seemed to have the same overall objective and thus worked toward a shared goal in different parts of the procedure and, therefore, could be seen as one team with a holistic view at the entire procedure. This was most obvious in Act 2 where the extensive preventive safety work occurred. Some examples of these safety activities were the placement of foam cushions under the patient to prevent pressure ulcers and stabilization of the patient in a way to avoid falling, both involving all nursing staff. The hygienical preparation of the patient, staff and the room could be categorized as multiprofessional, but, in a way, this could also be interprofessional when the OR nurse and the radiographer collaborated and the boundary between their activities was not strict. Ensuring patient safety has been reported as the main focus for the OR nurse $^{31}$ and nurse anesthetist, ${ }^{32}$ and our study also found this to be accurate. Radiation protection was mainly 


\begin{tabular}{|c|c|c|}
\hline $\begin{array}{l}\text { Multiprofessional } \\
\text { activities }\end{array}$ & $\begin{array}{l}\text { Interprofessional } \\
\text { activities }\end{array}$ & $\begin{array}{c}\text { Transprofessional } \\
\text { activities }\end{array}$ \\
\hline $\begin{array}{l}\text { - Tracheal intubation } \\
\text { - Artery puncture } \\
\text { - preparing radiation } \\
\text { protection } \\
\text { - Hygienical preparation } \\
\text { of the patient } \\
\text { - Ultrasound } \\
\text { - examination } \\
\text { - Skin incision } \\
\text { - Wound closure } \\
\text { - Material preparation } \\
\text { - Awaking of patient }\end{array}$ & $\begin{array}{l}\text { - Patient positioning } \\
\text { - Safety preparations } \\
\text { like stabilizing the } \\
\text { patient, placing foam } \\
\text { cushions to prevent } \\
\text { pressure ulcers }\end{array}$ & $\begin{array}{l}\text { - Patient transfer } \\
\text { - Time out procedure }\end{array}$ \\
\hline
\end{tabular}

Figure 3 Examples of types of cross-professional activities conducted in the hybrid operating room.

a multiprofessional activity where the radiographer had a clear responsibility, both for the staff and for the patient. ${ }^{33}$ This was verified by the way they moved different protective devices and shields to the "right" place, and how they verbally instructed the rest of the staff about radiation protection. Preparing radiation protection could in a way be an interprofessional activity because this issue seemed to interest and involve several staff categories. Understanding their own and others' roles and responsibilities promoted interprofessional work in line with previous research. ${ }^{34}$ In parts of the procedure, the staff worked simultaneously with different activities, but sometimes one activity had to be completed before the next could start, illustrating a mutual interdependency between the staff in the room. ${ }^{26}$ This appeared in all Acts during the whole procedure and was understood as a know-how practice, which was shared by all involved as some kind of silent agreement and shared knowledge. ${ }^{23}$ Hence, considerable waiting times were identified in different parts of the procedure especially in Act 3. The radiographer had the main role in the interventional procedure, while the OR nurse had a standby position during almost the whole of Act 3. It was, however, evident that the main operators were generally active while present in the room, reflecting a more time-efficient use of the operators.

\section{Transprofessional activities involving all staff}

The staff performed their activities and tasks simultaneously while directed toward a mutual goal, such as moving the patient to the OR table which was a transprofessional activity. Professionals with a common goal, the patient's welfare, are able to work well together to achieve this goal. ${ }^{26,34}$ Patient transfer from the wheeled bed to the OR table was a shared transprofessional activity that involved everyone independent of their professional roles and positions in the hybrid OR. In this phase of the procedure, it seemed that all involved staff were concentrating on the same goal: to provide the patient with a correct, secure and comfortable transfer and position on the OR table. The "time-out procedure" was an additional transprofessional activity where all staff in the room participated.

\section{Methodological considerations}

It is important to keep in mind that the results of this study are not necessarily valid for other EVAR contexts. Generalization may, therefore, be difficult, but the results may still be of interest for other or similar environments. Data for this study were collected by video/audio recordings of image-guided interventions performed in a hybrid OR. Video recording of work and interaction in hospital settings, such as surgical operations, enables researchers to address a range of phenomena that previously remained largely unexplored. ${ }^{35}$ Several previous studies have utilized this method in the hospital environment. $^{25,36}$ The three main disadvantages of video recording $\mathrm{OR}$ procedures are the ethical issues connected with registration of human beings, costs associated with the camera equipment and the overwhelming amount of data. ${ }^{35}$ However, video recording offers major advantages including data that can be shared and observed repeatedly, which is impossible if based only on live observations. The researchers were not 
physically present in the hybrid OR during the recordings, but all staff present in the hybrid OR were aware of the cameras and the study's objectives. This raises the question of how this could have influenced behavior. However, the researcher's effect on behavior was judged to be limited in this study, partly because the researcher was not located in the hybrid OR during the recordings. Nevertheless, it cannot be ruled out that some participants (staff) may have been more self-conscious or rigid to protocol in front of the video cameras than they would otherwise be. ${ }^{37}$ It seems unlikely, however, that the staff could have had the researcher and cameras in mind for a long period of time since they had to focus on their tasks during the treatment.

The videos were analyzed qualitatively with an inductive approach, and the observers' relationship between preunderstanding and openness can be discussed. One of the strengths of the study was that the video recordings were observed by three researchers with different backgrounds, and the very awareness of preunderstanding might have reduced this effect.

\section{Conclusion}

In conclusion, this study emphasizes that the professional expertise from all three specialties (anesthesia, surgery and radiology) was required for the treatment to be carried out and to ensure patient safety, but the extent of interprofessional activities was limited and the staff largely worked in separate teams. The degree and type of collaboration depended on the actual activity and was more or less obvious across the procedure. Our results provide a basis for the development of more effective procedures with closer and more efficient interprofessional collaboration. This could be achieved by more training in working as a cohesive team and with clearly defined roles. A question this study raised was if the material could be placed more strategically so that the staff movement in the room, especially during Act 2, could be reduced and promote more collaboration. Even if the traffic flow was not specifically evaluated in this study, it was considered to be high. This study provides significant information to consider when building and staffing a hybrid OR in the future. It also provides information that could be valuable in academic discussions about renewed education programs. The study highlights specific issues in relation to patient safety that should be further investigated. These include collaboration and communication, traffic flow and door openings and the presence of unnecessary persons in a hybrid OR.

\section{Acknowledgments}

The authors would like to express their gratitude to all patients and staff who agreed to participate in the study. We also thank Maud Lundén for reading the manuscript and giving helpful advice. We are also grateful to Christie Tetreault for editorial assistance and language corrections.

\section{Disclosure}

The authors report no conflicts of interest in this work.

\section{References}

1. Field ML, Sammut J, Kuduvalli M, Oo A, Rashid. A Hybrid theatres: nicety or necessity? J R Soc Med. 2009;102(3):92-97. doi:10.1258/ jrsm.2009.080390

2. Kaneko T, Davidson MJ. Use of the hybrid operating room in cardiovascular medicine. Circulation. 2014;130(11):910-917. doi:10.1161/CIRCULATIONAHA.114.006510

3. Nollert G, Hartkens T, Figel A, Bulitta C, Altenbeck F, Gerhard V. The hybrid operating room.In: Narin C, editor. Special Topics in Cardiac Surgery. Rijeka: InTech; 2012. Available from: https:// www.intechopen.com/books/special-topics-in-cardiac-surgery/thehybrid-operating-room

4. SBU. Vad finns beskrivet i litteraturen om nyttan med hybridsalar? Stockholm: SBU; 2011. Available from: http://www.sbu.se/sv/publika tioner/sbus-upplysningstjanst/vad_finns_beskrivet_om_nyttan_med_ hybridsalar/. Accessed May 2, 2019.

5. Benjamin M. Building a modern endovascular suite. Endovac Today. 2008;3:71-78.

6. Jacob AL, Regazzoni P, Bilecen D, Rasmus M, Huegli RW, Messmer P Medical technology integration: CT, angiography, imaging-capable OR-table, navigation and robotics in a multifunctional sterile suite. Minim Invasive Ther Allied Technol. 2007;16(4):205-211. doi:10.1080/13645700701520628

7. Sikkink CJJM, Reijnen MMPJ, Zeebregts CJ. The creation of the optimal dedicated endovascular suite. Eur J Vasc Endovasc Surg. 2008;35(2):198-204. doi:10.1016/j.ejvs.2007.08.009

8. Gofrit O, Weissman C, Peleg E, Lifshits N, Pinchover R, Weiss Y. Designing a modern surgicalfacility. Perioper Care Oper Room Manag. 2016;3:12-20. doi:10.1016/j.pcorm.2016.05.007

9. Tomaszewski R. Planning a better operating room suite: design and implementation strategies for success. Perioper Nurs Clin. 2008;3 (1):43-54. doi:10.1016/j.cpen.2007.11.005

10. D’Amours SK, Rastogi P, Ball CG. Utility of simultaneous interventional radiology and operative surgery in a dedicated suite for seriously injured patients. Curr Opin Crit Care. 2013;19(6):587-593. doi:10.1097/MCC.0000000000000031

11. Iihara K, Satow T, Matsushige T, et al. Hybrid operating room for the treatment of complex neurovascular and brachiocephalic lesions. J Stroke Cerebrovasc Dis. 2013;22(8):e277-e285. doi:10.1016/j. jstrokecerebrovasdis.2012.07.014.

12. Tsagakis K, Konorza T, Dohle DS, et al. Hybrid operating room concept for combined diagnostics, intervention and surgery in acute type a dissection. Eur J Cardiothorac Surg. 2013;43(2):397-404. doi:10.1093/ejcts/ezs287

13. Traversari AAL, Spm VH, Hoksbergen AWJ. Effect of using ceiling-mounted systems for imaging in hybrid operating rooms on the level of colony-forming units during surgery. J Hosp Infect. 2018. doi:10.1016/j.jhin.2018.10.016

14. Kvarnström S. Difficulties in collaboration: A critical incident study of interprofessional healthcare teamwork. J Interprof Care. 2008;22 (2):191-203. doi:10.1080/13561820701760600 
15. Thylefors I, Persson O, Hellström D. Team types, perceived efficiency and team climate in Swedish cross-professional teamwork. $J$ Interprof Care. 2005;19(2):102-114. doi:10.1080/ 13561820400024159

16. Hall P, Weaver L. Interdisciplinary education and teamwork: a long and winding road. Med Educ. 2001;35(9):867-875.

17. Schaadt J, Landau B. Hybrid OR 101: a primer for the OR nurse. Aorn J. 2013;97(1):81-100. doi:10.1016/j.aorn.2012.10.009

18. Eder SP, Register JL. 10 management considerations for implementing an endovascular hybrid OR. Aorn J. 2014;100(3):260-270. doi:10.1016/j.aorn.2014.07.002

19. Miller T. The hybrid challenge. Planning for imaging-enabled operating rooms. Health Facil Manage. 2012;25(7):23-27.

20. Einarsson C, Hammar Chiriac E. Gruppobservationer : Teori och praktik. Johanneshov: TPB; 2009.

21. Gadamer H-G. Truth and Method. New York: Continuum; 1994.

22. Yin RK. Case Study Research: Designand Methods. London: SAGE; 2009.

23. Benner P. From Novice to Expert: Excellenceand Power in Clinical Nursing Practice. Menlo Park, Calif.: Addison-Wesley; 1984.

24. Emami A. "We Are Deaf, Though We Hear; We Are Dumb, Though We Talk; We Are Blind, Though We See”: Understanding Iranian Late-In-Life Immigrants' Perceptions and Experiences of Health, Illness and Culturally Appropriate Care. Stockholm: Karolinska Institutet; 2000.

25. Melheim A. Bevegelsens lindring - lindringens bevegelse: Omsorgssamtalemed barn. Åbo: Åbo Akademis förlag; 2014.

26. Thylefors I. Babels torn: Om tvärprofessionellt teamsamarbete. Johanneshov: MTM; 2014.

27. Helsinki Declaration. Ethical principles for medical research involving human subjects; 1964. Available from: https://www.wma.net/ policies-post/wma-declaration-of-helsinki-ethical-principles-formedical-research-involving-human-subjects/. Accessed May 2, 2019.
28. Arkivlagen (1990:782). Stockholm: Socialdepartementet doi:10.1099/00221287-136-2-327. Available from: https://www.riks dagen.se/sv/dokument-lagar/dokument/svensk-forfattningssamling/ arkivlag-1990782_sfs-1990-782. Accessed 20 May, 2019.

29. Collette AE, Wann K, Nevin ML, et al. An exploration of nurse-physician perceptions of collaborative behaviour. J Interprof Care. 2017;31(4):470-478. doi:10.1080/13561820.2017.1301411

30. Rydenfalt C, Johansson G, Larsson PA, Akerman K, Odenrick P. Social structures in the operating theatre: how contradicting rationalities and trust affect work. $J$ Adv Nurs. 2012;68(4):783-795. doi:10.1111/j.1365-2648.2011.05779.x

31. Alfredsdottir H, Bjornsdottir K. Nursing and patient safety in the operating room. J Adv Nurs. 2008;61(1):29-37. doi:10.1111/j.13652648.2007.04462.x

32. Aagaard K, Laursen BS, Rasmussen BS, Sorensen EE. Interaction between nurse anesthetists and patients in a highly technological environment. J Perianesth Nurs. 2017;32(5):453-463. doi:10.1016/ j.jopan.2016.02.010

33. Williams H, Widdowfield M, Cosson P. The radiographer's multidisciplinary team role in theatre scenarios. Radiography. 2015;21 (2):165-171167p. doi:10.1016/j.radi.2014.10.003

34. Strudwick RM, Day J. Interprofessional working in diagnostic radiography. Radiography. 2014;20(3):235-240. doi:10.1016/j. radi.2014.03.009

35. Heath C, Hindmarsh J, Luff P. Video in Qualitative Research: Analyzing social Interaction in Everyday Life. Los Angeles: SAGE; 2010 .

36. Karlsson FA, Bergbom I. Communication when patients are conscious during respirator treatment-A hermeneutic observation study. Intensiv Crit Care Nurs. 2012;28(4):197-207. doi:10.1016/j. iccn.2011.12.007

37. Polit DF, Beck CT. Nursing Research: Generating and Assessing Evidence for Nursing Practice. Philadelphia: Wolters Kluwer Health/Lippincott Williams \& Wilkins; 2012. 


\section{Supplementary materials}

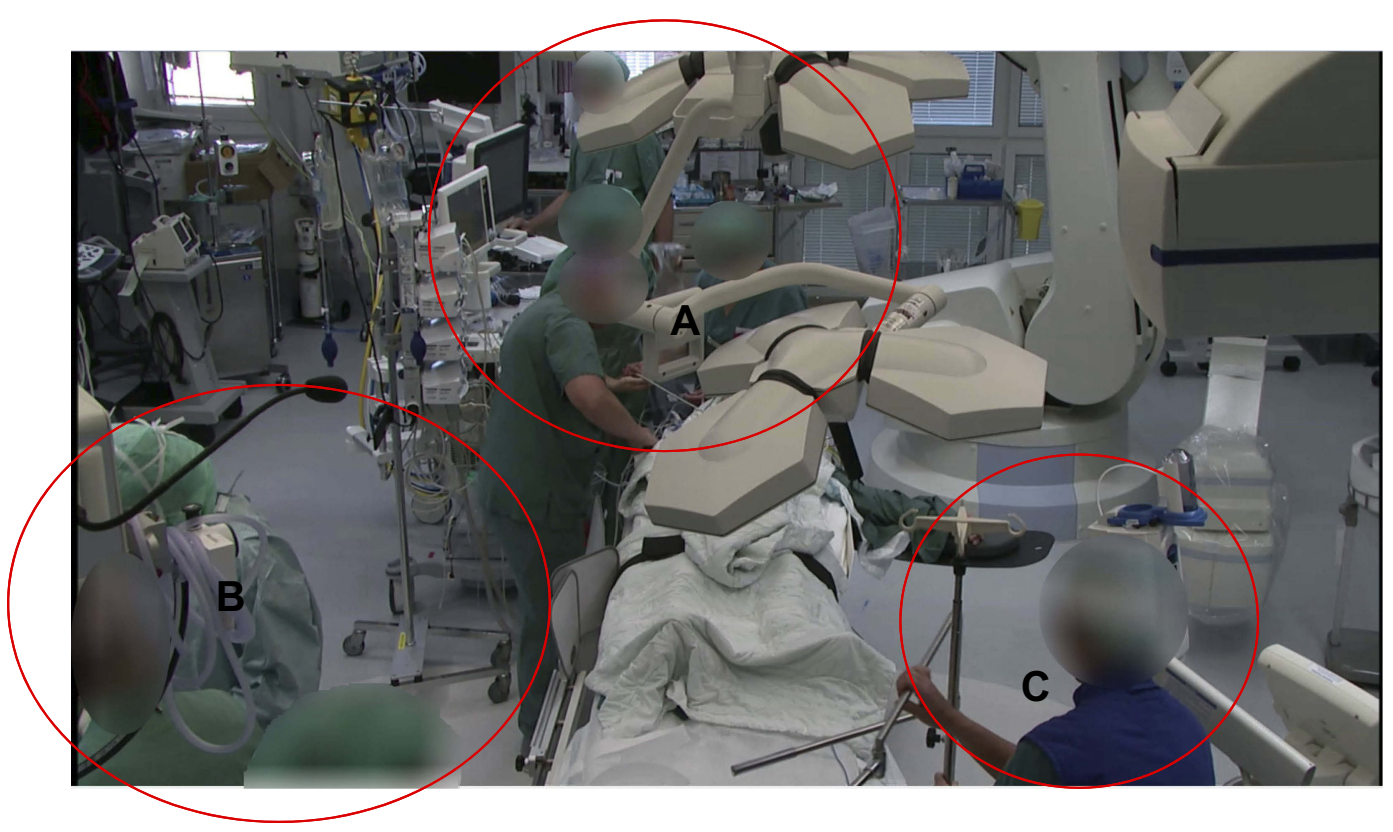

Figure SI Activities that take place simultaneously and in separate locations in Act 2. At the top and middle of the picture (area A), the nurse anesthetists are visibly preparing the patient. To the left (area B), the operating room (OR) nurses and assistant nurse are preparing material, while a radiographer (area $\mathbf{C}$ ) is engaged in preparing the contrast injector.

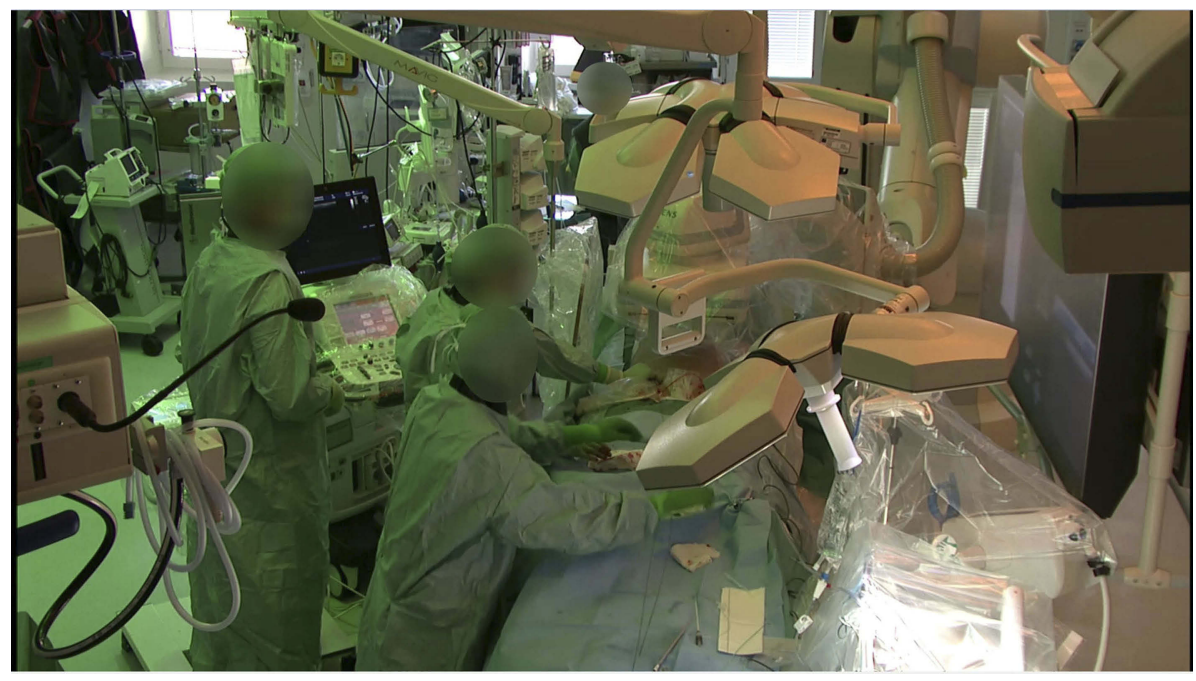

Figure S2 Two operators (A) and one radiographer (B) standing closest to the patient in Act 3.

Journal of Multidisciplinary Healthcare

Dovepress

\section{Publish your work in this journal}

The Journal of Multidisciplinary Healthcare is an international, peerreviewed open-access journal that aims to represent and publish research in healthcare areas delivered by practitioners of different disciplines. This includes studies and reviews conducted by multidisciplinary teams as well as research which evaluates the results or conduct of such teams or healthcare processes in general. The journal covers a very wide range of areas and welcomes submissions from practitioners at all levels, from all over the world. The manuscrip management system is completely online and includes a very quick and fair peer-review system. Visit http://www.dovepress.com/testimonials. php to read real quotes from published authors. 